\title{
Evaluation of sedative and anxiolytic activities of methanol extract of leaves of Persicaria hydropiper in mice
}

\author{
Md. Shahed-Al-Mahmud*io and Shah Marzia Mahjabin Lina
}

\begin{abstract}
Background: Persicaria hydropiper Linn. (Family: Polygonaceae), it grows in damp places and the bank of rivers, canals, lakes, and roadsides of Bangladesh. The leaves of the plant used in traditional medicine to treat insomnia, depression, and neurodegenerative diseases. The objective of this study is to investigate the sedative and anxiolytic activities of the methanol extract of leaves of Persicaria hydropiper (MEPH).

Methods: The sedative effect of the P. hydropiper at the doses of 50, 200, 350, and $500 \mathrm{mg} / \mathrm{kg}$ evaluated using the open field, hole cross, rota-rod and thiopental sodium-induced sleeping time test in mice. The anxiolytic activity evaluated using the elevated-plus maze, light-dark box, hole-board and marble-burying test. Sedative and anxiolytic activities compared to diazepam, a positive control. The acute toxicity test also assessed.

Results: The neuropharmacological activity of both open field and hole cross tests significant $(p<0.001)$ decrease the number of (square and hole) crosses by mice compare to control group. The rota-rod test to evaluate the motor coordination or muscle relaxant significantly $(p<0.001)$ increases the number of falling whereas decrease performance time from the rotating rod. In thiopental sodium-induced sleeping test, MEPH causes a decrease in the sleep latency time and significantly $(p<0.001)$ increase the duration of sleeping time. In the elevated plus-maze test, the different parameters (the time spent and the number of entries in open arms; the time spent and the number of entries in close arms) observed. Treatment with MEPH significant $(p<0.001)$ increase the time spent and the number of entries in open arms comparable to control group. In respect of the light-dark box test, several (latency times, the number of transitions, the time spent in the light and dark compartment) parameters also observed. Mice treated with MEPH significant $(p<0.001)$ increase the time spent in the light compartment compared to control group. The hole-board tests, MEPH significant $(p<0.001)$ decrease the number of head dips, as well as the number of marbles burying, was significant $(p<0.001)$ decrease in the marble-burying test showing anxiolytic activity.
\end{abstract}

Conclusion: The results indicate that MEPH has sedative and anxiolytic activities, supporting its uses in traditional medicine. Further studies of the isolation of the active components of $P$. hydropiper and its mechanism of action study strongly recommended before the application in human.

Keywords: Persicaria hydropiper Linn, Polygonaceae, Sedative, Anxiolytic, Thiopental sodium-induced sleeping test, Neuropharmacological

\footnotetext{
* Correspondence: shahed.shuvo16@gmail.com

Department of Pharmacy, Stamford University Bangladesh, 51, Siddeswari

Road, Dhaka -1217, Bangladesh
} 


\section{Background}

Persicaria hydropiper Linn. Delarbre is an ordinary plant of the Polygonaceae family regionally known as "Bishkatali" in Bangladesh. Persicaria, a clad in Polygonaceae containing approximately 120 species, grows on the edge of rivers, canals, lakes, and besides the road of tropical and sub-tropical countries of Asia [1]. P hydropiper decoctions are used in the treatment of various ailments including inflammation, dyspepsia, diarrhea, menorrhagia, hemorrhoids, helminthiasis and CNS disorders [2]. The leaves of $P$. hydropiper is used as carminative, astringent, diuretic and significant CNS depressant activities [3]. The leave's juice has been given for treating various illnesses such as a headache, pain, toothache, gastric ulcer, dysentery, anorexia, and dysmenorrhea while the roots are used as a CNS depressant and its juice is applied to wounds and skin diseases [4]. In Bangladesh, the Garo tribe uses the leave's juice for the relief of anxiety and insomnia taken usually as a single dose before sleeping [5]. Tripura another tribe of Bangladesh uses the mixture of crushed $P$. hydropiper leaves for convulsion, insomnia and anxiety [6]. The Hill tract zone of Bangladesh, the crushed plant helps to inhibit insomnia and in Rema Kalenga, the leaves are used for sedation and tranquilizers [7]. The plant has been reported to possess as bitter, tonic, diuretic, carminative and hemostatic properties [8]. Research has been focused on the biological effects of plant's part, which have been used as cholinesterase inhibitors [9]. It lately has reported that $P$. hydropiper for antioxidant, anticholinesterase activities and its dynamic use for the treatment of neurodegenerative diseases [10].

A few compounds such as alkaloids, flavonoids, carbohydrates, glycosides, tannins, saponins and steroids have been isolated from $P$. hydropiper. Flavonoids are able to influence central nervous system activity (CNS) by binding to the benzodiazepine site on the $\mathrm{GABA}_{\mathrm{A}}$ receptor resulting in sedation, anxiolytic effects [11]. Several bioactive constituents have also been indicated from $P$. hydropiper with antihyperglycemic [12], antioxidant [13], antinociceptive [8], anti-inflammatory [14], cytotoxicity and anthelmintic activities [2].

It is explicit on the existing knowledge that the genus $P$. hydropiper is affluent in active biologic compounds. Although P. hydropiper is widely used an ethnomedicinal plant and deep-drawing phytochemical analysis were conveyed out on it biologics evaluation of $P$. hydropiper. In-vitro neuropharmacological activities of $P$. hydropiper has been performed [15]. On the basis of that evidence, the present study is focused on $P$. hydropiper leaves exert in sedative and anxiolytic activities on Central Nervous System (CNS) in different models in mice.

\section{Methods}

\section{Plant material}

The plant $P$. hydropiper collected from the Simantobazar road side of Sirajganj district, Bangladesh during August 2014 at the daytime. The plant identified by the experts of Bangladesh National Herbarium at Mirpur in Dhaka (Accession no. DACB 39853) and a voucher specimen deposited at the Pharmacy Department, Stamford University Bangladesh. The date of the investigation done by Bangladesh National Herbarium on 12th August 2014.

\section{Preparation of the plant extract}

The shed dried leaves were ground separately by commercial grinder (Hammer mill) into a fine powder and about $120 \mathrm{~g}$ of each powered materials macerated with methanol and occasional shaking in $900 \mathrm{~mL}$ methanol in a beaker at $25 \pm 2{ }^{\circ} \mathrm{C}$ for $72 \mathrm{~h}$ and stirred every $18 \mathrm{~h}$ using a sterile glass rod. Methanol used for extraction of bioactive compounds from Plants belong to various chemical groups such as alkaloids, glycosides, tannins, and flavonoids, steroid and so on. Methanol has a polarity index of 5.1 and lowers boiling point than other organic solvents. Methanol would give a higher yield compared to other organic solvents. The whole mixtures then underwent a coarse filtration by a piece of clean and white sterilized cotton material. These filtered through Whatman 102 filter paper. The filtrates evaporated under (BC-R 201 Shanghai Biochemical Equipment Co. Ltd.) rotary evaporator. After drying, $20.7 \mathrm{~g}$ of dried extract (yield 17.82\%) obtained from $120 \mathrm{~g}$ of powder. The methanol extract of $P$. hydropiper subjected to the investigations of sedative and anxiolytic activity studies.

\section{Animals}

Adult male Swiss albino mice (20-25 g) collected from the Animal Research Branch of the International Center for Diarrheal Disease and Research, Bangladesh (ICDDR, B). The standard environmental condition maintained for mice (temperature: $25 \pm 2{ }^{\circ} \mathrm{C}$, humidity: $55-65 \%$ and $12 \mathrm{~h} \mathrm{light/dark}$ cycle). Foods of mice collected from ICDDR, B had given to the mice with water. Mice acclimatized to the laboratory environment over a period of seven days before performing the experiments. No food was given to the animals overnight before the experiments. Every experiment associated with new cohorts of mice. We calculated the average body weight of mice for the experiments. All the 
experimental mice treatment followed the Ethical Principles and Guidelines for Scientific Experiments on Animals (1995) formulated by The Swiss Academy of Medical Sciences and the Swiss Academy of Sciences.

\section{Treatments}

The methanol extract of $P$. hydropiper suspended in 0.9\% physiological saline. Diazepam (Square Pharmaceuticals Ltd.) used as the positive control group for all test. The drugs collected from a local medicine shop. The described experiments used reagents such as methanol (Merck, Germany) and saline water (Opsonin Pharma Ltd. Bangladesh). Test groups of mice treated orally (p. o.) with methanol extract of $P$. hydropiper $(0.1 \mathrm{~mL} /$ mouse $)$ at the doses of $50,200,350$, and $500 \mathrm{mg} / \mathrm{kg}$ whereas the control group received $0.9 \%$ physiological saline $(0.1 \mathrm{~mL} /$ mouse $)$ by the same routes. The positive control group received diazepam $(1 \mathrm{mg} / \mathrm{kg})$ was also administered the intraperitoneal $(0.1 \mathrm{~mL} /$ mouse $)$ $30 \mathrm{~min}$ before the experiments. All the groups received drug and samples via gavages and syringes. All other chemicals and reagents were of analytical grade and high purity.

\section{Acute toxicity test}

Swiss albino arranged into six test groups and a control group $(n=10)$ within the weight of $20-25 \mathrm{~g}$. $0.9 \%$ physiological saline used for the control group (0.1 mL/mouse). The test groups received in 100,250 , $400,500,750$, and $1000 \mathrm{mg} / \mathrm{kg}$ doses of the methanol extract of $P$. hydropiper respectively through the oral route. After gavages, the animals kept in separate cages and allowed for food and water ad libitum. The animal's observations continued for the next $72 \mathrm{~h}$ for any abnormal behaviors, allergic symptoms (skin, rash, itching), and mortality [16].

\section{Phytochemical screening}

Upon conducting standard procedures, preliminary phytochemical screening of MEPH was qualitatively test carried out for the detection of alkaloids, flavonoids, carbohydrates, glycosides, tannins, Saponins and steroids [17].

\section{Sedative activity test Open field test}

The open field behavioral test is routinely used to conduct both locomotor activities and emotionally in rodents [18]. Animals divided into control, positive control, and test group. The apparatus made by plywood $(72 \mathrm{~cm} \times 72 \mathrm{~cm} \times 36 \mathrm{~cm})$. In the board, an open field of half square meter divided into a series of squares, each alternatively colored (black and white). The floor of open field apparatus made by cardboard which divided into 16 squares $(18 \mathrm{~cm} \times 18 \mathrm{~cm})$. This observation was done at room temperature under the lighting condition. The number of squares passed anyway by the animal counted for 3 min started at 0 , 30, 60, 90 and 120 min after oral administration of the test drugs.

\section{Hole cross test}

The most consistent behavioral change is a hyperemotional response to a novel environment [19]. A partition fixed in the middle of a cage having a size of $30 \times 20 \times 14 \mathrm{~cm}^{3}$. The apparatus made by wooden board. A hole of $3 \mathrm{~cm}$ diameter made from a height of $7.5 \mathrm{~cm}$ in the center of the cage. Treated mice placed in the center of one side of the cage. Then the number of passages of a mouse through the hole from one compartment to another compartment counted over a period of $3 \mathrm{~min}$ at $0,30,60,90$ and 120 min after the administration.

\section{Rota-rod test}

The motor coordination and performance of each new cohort of the mouse was evaluated $30 \mathrm{~min}$ after oral treatment of MEPH in a rota-rod apparatus. Mice were placed on a horizontal wooden rod rotating at a speed of $20 \mathrm{rpm}$. The selected animals divided into six groups $(n=10)$. The mice trained before the experiment for $180 \mathrm{~s}$ on rota-rod. The test groups received MEPH orally whereas the control group received $0.9 \%$ physiological saline. Animals in the positive control group received diazepam $(1 \mathrm{mg} /$ $\mathrm{kg}$ ). The animals placed in rotating bar $2.5 \mathrm{~cm}$ in diameter and $25 \mathrm{~cm}$ height from the floor. Each mice observation time was $180 \mathrm{~s}$ which considers as performance time and failed more than once to remain on the rota-rod considered as passed the test [20].

\section{Thiopental sodium-induced sleeping time test}

The animals were randomly divided into control, positive control and test groups consisting of ten mice each group [18]. The test groups received MEPH orally whereas the control group received $0.9 \%$ physiological saline. Animals in the positive control group received diazepam $(1 \mathrm{mg} / \mathrm{kg}) .30 \mathrm{~min}$ later, thiopental sodium $(40 \mathrm{mg} / \mathrm{kg}$, i.p.) was administered to each mouse to induce sleep. The animals were observed for the latent period (time between Thiopental sodium administrations to loss of righting reflex) and duration of sleep (the time between the loss and recovery of righting reflex). 
Table 1 Preliminary qualitative phytochemical screening of $\mathrm{MEPH}$

\begin{tabular}{lll}
\hline Phytochemical constituents & Tests & Inferences \\
\hline Alkaloids & Mayer's test & + \\
& Dragendorf's test & + \\
Flavonoids & Lead acetate test & + \\
Carbohydrates & Molisch's test & + \\
& Fehling's test & + \\
Glycosides & Modified borntrager's test & + \\
Tannins & Gelatin test & + \\
Saponins & Frothing test & + \\
& Foam test & + \\
Steroids & Libermann burchard's test & + \\
\hline
\end{tabular}

Key: + present

\section{Anxiolytic activity test}

\section{Elevated plus-maze test}

The plus maze apparatus consisting of two open arms $(16 \times 5 \times 12 \mathrm{~cm})$ and two closed arms $(16 \times 5 \times 12 \mathrm{~cm})$ with an open roof which was $50 \mathrm{~cm}$ elevated from the floor used to observe anxiolytic behavior in animals [19]. Each new cohort of the mouse placed on the elevated plus-maze apparatus 30 min after the administration of the dose. Each mouse placed in the center of the elevated plus-maze with its head facing the open arms. The behavioral effects of the mouse observed for 5 min with a different kind of parameter (time spent in open arms, time spent in the close arms, the number of the entry in the open arms, the number of the entry in the close arms).

\section{Light-dark box test}

The light-dark test may be useful to predict anxiolytic-like or anxiogenic-like activity in mice. Transitions have been reported to be an index of activity-exploration because of habituation over time, and the time spent in each compartment to be a reflection of aversion [20]. This consist of a fully automated box monitored by the observer. An opentopped rectangular box $(46 \times 27 \times 30 \mathrm{~cm}$ high $)$ divided into a small $(18 \times 27 \mathrm{~cm})$ area and a large $(27 \times 27 \mathrm{~cm})$ area with an opening door $(7.5 \times 7.5 \mathrm{~cm})$ located at the center of the partition at the floor level. One compartment painted black and dark environment whereas the large compartment was painted white and brightly illuminated by a $60-\mathrm{W}$ (400 lx) light source. The light placed in the center of the white compartment. The time spent in the illuminated and dark compartment, as well as the number of transitions in each space, the latency of the first crossing from one compartment to the other, recorded for $5 \mathrm{~min}$. The environment during the test was the dark condition. The data for these four parameters directly collected by the observer. This test exploited the conflict between the animal's tendency to explore a new environment and its fear of bright light [21].

\section{Hole-board test}

The apparatus was composed of a gray wooden box $(40 \mathrm{~cm} \times 40 \mathrm{~cm} \times 25 \mathrm{~cm})$ with sixteen equidistant holes $3 \mathrm{~cm}$ in diameter on the floor [22]. The center of each hole was $10 \mathrm{~cm}$ from the nearest wall of the box. The floor of the box was positioned $15 \mathrm{~cm}$ above the ground and divided into squares of $(10 \mathrm{~cm} \times 10 \mathrm{~cm})$ with a water-resistant marker. An

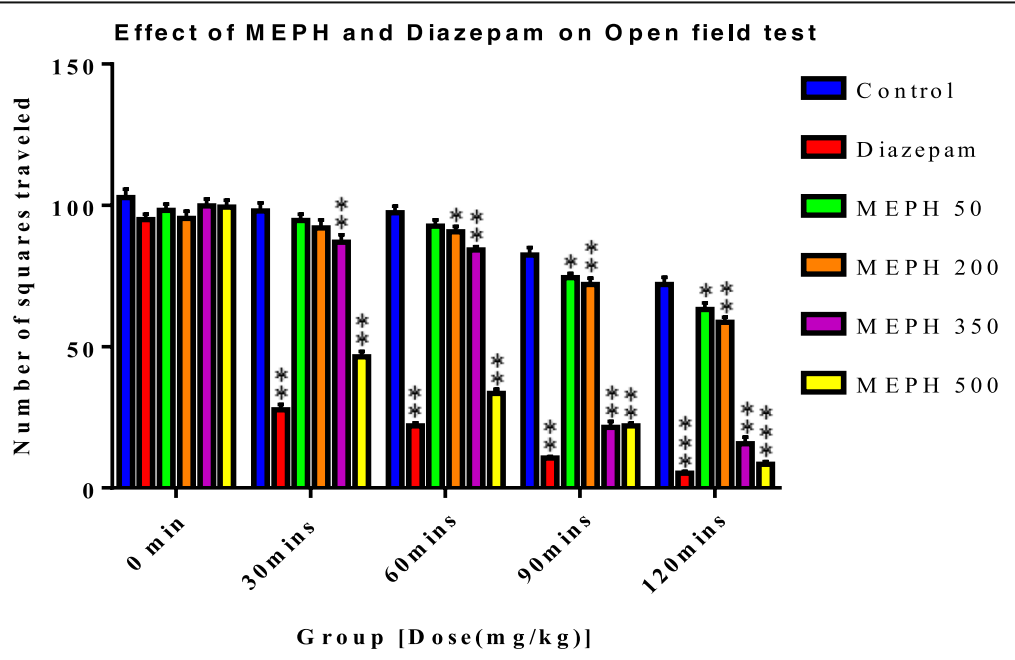

Fig. 1 The effect of MEPH on the open field test (number of square crossed at 0 min, 30 mins, 60 mins, 90 mins and 120 mins) in mice 
Table 2 The effect of MEPH on the open field test in mice

\begin{tabular}{|c|c|c|c|c|c|c|}
\hline \multirow{2}{*}{ Treatment } & \multirow[t]{2}{*}{ Dose (mg/kg) } & \multicolumn{5}{|c|}{ Number of squares crossed } \\
\hline & & $0 \mathrm{~min}$. & 30 mins. & 60 mins. & 90 mins. & 120 mins. \\
\hline Control & $0.1 \mathrm{ml} / \mathrm{mouse}$ & $102.80 \pm 2.92$ & $98.00 \pm 2.81$ & $97.40 \pm 2.27$ & $82.40 \pm 2.69$ & $72.00 \pm 2.55$ \\
\hline Diazepam & 1 & $95.00 \pm 1.84$ & $27.60 \pm 1.91^{* * *}$ & $22.00 \pm 1.00^{* * *}$ & $10.60 \pm 0.51^{* * *}$ & $5.20 \pm 0.66^{* * *}$ \\
\hline MEPH & 50 & $98.20 \pm 2.26$ & $94.60 \pm 2.24$ & $92.60 \pm 2.29$ & $74.40 \pm 1.47^{*}$ & $63.20 \pm 2.31^{*}$ \\
\hline MEPH & 200 & $95.40 \pm 2.40$ & $92.00 \pm 2.89$ & $90.60 \pm 1.96^{*}$ & $72.00 \pm 2.25^{* *}$ & $58.60 \pm 1.83^{* * *}$ \\
\hline MEPH & 350 & $99.80 \pm 2.43$ & $87.00 \pm 2.58^{* *}$ & $84.20 \pm 1.15^{* * *}$ & $21.40 \pm 2.11^{* * *}$ & $15.60 \pm 2.31^{* * *}$ \\
\hline MEPH & 500 & $99.40 \pm 2.42$ & $46.40 \pm 1.88^{* * *}$ & $33.40 \pm 1.47^{* * *}$ & $22.00 \pm 0.89^{* * *}$ & $8.40 \pm 0.87^{* * *}$ \\
\hline
\end{tabular}

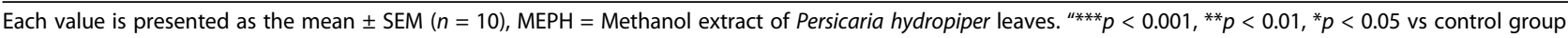
(Dunnett's test)"

animal placed at the center of the hole-board and allowed to explore the apparatus for $5 \mathrm{~min}$. The total number of heads-dips recorded. The head dip scored if both eyes disappeared into the hole.

\section{Marble-burying test}

Mice placed individually in glass cages with the designated bedding material for $30 \mathrm{~min}$ (habituation period) and then placed into waiting in cages [23]. Twenty-five glass marbles positioned evenly spaced $7 \mathrm{~cm}$ apart on a $4 \mathrm{~cm}$ layer of bedding material in the habituation cages. The mice introduced in the same cage in which they habituated before the experiment. After $30 \mathrm{~min}$, the marble burying period concluded by removing the mouse, and the number of marbles that more than twothirds covered with bedding material counted. Whether a marble buried was established by experimenters and was confirmed by manual post-experimental assessment of an investigator. After each trial, cages and bedding materials replaced by fresh ones and glass marbles washed with water, dried with a paper towel, and left to return to room temperature.

\section{Statistical analysis}

The results presented as mean \pm SEM. The statistical analysis performed using one-way analysis of variance (ANOVA) followed by Dunnett's post hoc test as appropriate using SPSS 19 software whereas open field and hole cross tests analyzed by ANOVA with repeated measures. Differences between groups were considered significant at a level of $p<0.001, p<0.01$ and $p<0.05$.

\section{Results \\ Phytochemical screening}

The preliminary phytochemical screening of $\mathrm{MEPH}$ revealed the presence of alkaloids, flavonoids, carbohydrates, glycosides, tannins, saponins, and steroids (Table 1).

\section{Acute toxicity test}

According to oral administration of $\mathrm{MEPH}$ at the doses of $100-750 \mathrm{mg} / \mathrm{kg}$ did not shows any visible sign of delay toxicity, behavioral changes, allergic manifestations (skin, rash, itching) or mortality during

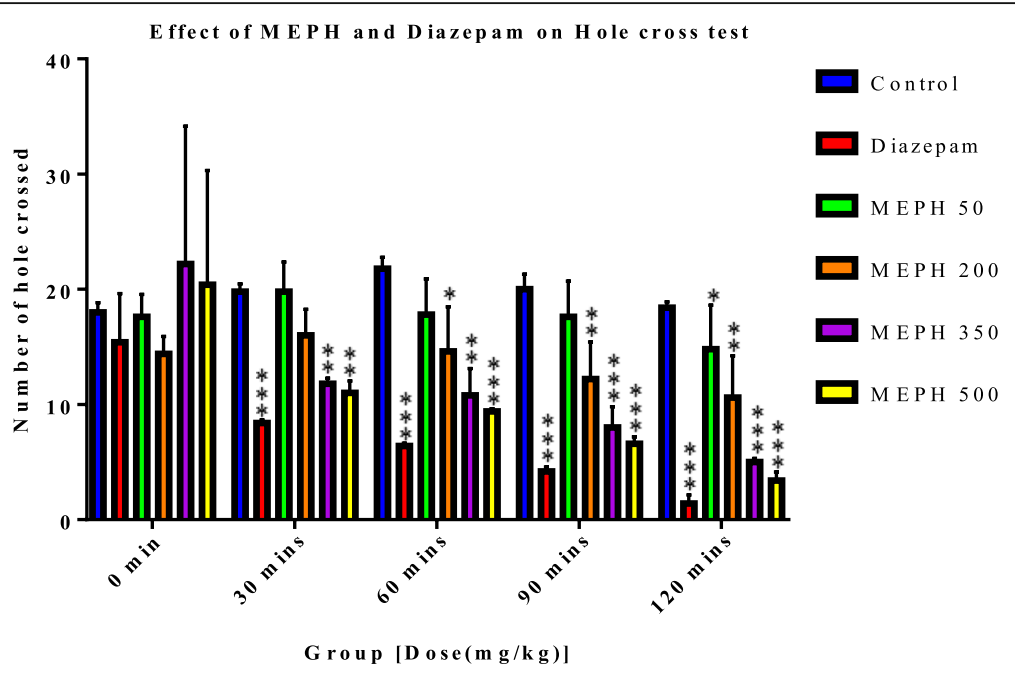

Fig. 2 The effect of MEPH on the hole cross test (number of hole crossed at 0 min, 30 mins, 60 mins, 90 mins and 120mins) in mice 
Table 3 The effect of MEPH on hole cross test in mice

\begin{tabular}{|c|c|c|c|c|c|c|}
\hline \multirow{2}{*}{ Treatment } & \multirow[t]{2}{*}{ Dose $(\mathrm{mg} / \mathrm{kg})$} & \multicolumn{5}{|c|}{ Number of holes crossed } \\
\hline & & $0 \mathrm{~min}$. & 30 mins. & 60 mins. & 90 mins. & 120 mins. \\
\hline Control & $0.1 \mathrm{ml} / \mathrm{mouse}$ & $18.00 \pm 0.83$ & $19.80 \pm 0.66$ & $21.80 \pm 0.97$ & $20.00 \pm 1.30$ & $18.40 \pm 0.51$ \\
\hline Diazepam & 1 & $8.60 \pm 0.24$ & $8.40 \pm 0.24^{* * *}$ & $6.40 \pm 0.24^{* * *}$ & $4.20 \pm 0.37^{* * *}$ & $1.40 \pm 0.74^{* * *}$ \\
\hline MEPH & 50 & $17.60 \pm 1.96$ & $19.80 \pm 2.57$ & $17.80 \pm 3.08$ & $17.60 \pm 3.10$ & $14.80 \pm 3.82^{*}$ \\
\hline MEPH & 200 & $14.40 \pm 1.50$ & $16.00 \pm 2.25$ & $14.60 \pm 3.86^{*}$ & $12.20 \pm 3.23^{* * *}$ & $10.60 \pm 3.62^{* * *}$ \\
\hline MEPH & 350 & $11.80 \pm 1.62$ & $11.80 \pm 0.49^{* *}$ & $10.80 \pm 2.33^{* * *}$ & $8.00 \pm 1.81^{* * *}$ & $5.00 \pm 0.31^{* * *}$ \\
\hline MEPH & 500 & $10.60 \pm 0.24$ & $11.00 \pm 1.04^{* * *}$ & $9.40 \pm 0.24^{* * *}$ & $6.60 \pm 0.60^{* * *}$ & $3.40 \pm 0.74^{* * *}$ \\
\hline
\end{tabular}

Each value is presented as the mean \pm SEM $(n=10), M E P H=$ Methanol extract of Persicaria hydropiper leaves. ${ }^{* * * *} p<0.001,{ }^{* *} p<0.01,{ }^{*} p<0.05$ vs control group (Dunnett's test)"

the $72 \mathrm{~h}$ observation periods. Therefore, it indicates that the MEPH possesses low toxicity profile and the $\mathrm{LD}_{50}$ is $750 \mathrm{mg} / \mathrm{kg}$.

\section{Sedative activity test \\ Open field test}

The number of squares crossed by the mice significantly $(p<0.05)$ at third observation $(60 \mathrm{~min})$ period. The movements of mice suppressed significantly $(p<0.01)$ during fourth $(90 \mathrm{~min})$ and fifth observation $(120 \mathrm{~min})$ period at $200 \mathrm{mg} / \mathrm{kg}$ (Fig. 1).The

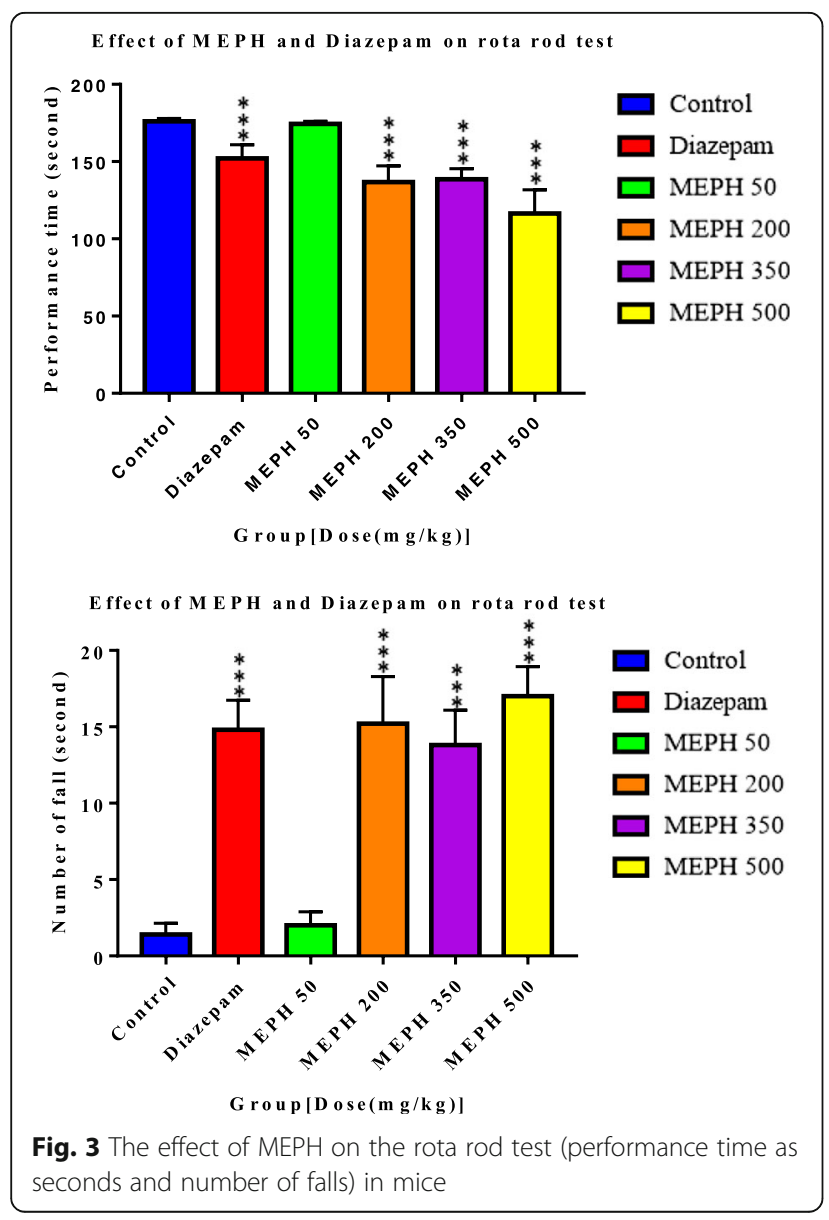

behavioral effects $(p<0.01)$ observed same from second $(30 \mathrm{~min})$ to fifth observation $(120 \mathrm{~min})$ periods at $350 \mathrm{mg} / \mathrm{kg}$ dose whereas, the movements significantly changed $(p<0.001)$ at $500 \mathrm{mg} / \mathrm{kg}$ in fifth observation $(120 \mathrm{~min})$ period. We observed that the sedative activity of the positive control group (diazepam $1 \mathrm{mg} / \mathrm{kg}$ ), induced almost similar modification as well as MEPH (Table 2).

\section{Hole cross test}

The number of holes crossed decreased significantly $(p<0.001)$ demonstrated for the fourth $(90 \mathrm{~min})$ and fifth $(120 \mathrm{~min})$ observation period at 200 and $350 \mathrm{mg} / \mathrm{kg}$ successively. We noticed that the hole cross activity significantly $(p<0.001)$ reduced by third $(60 \mathrm{~min})$ and continued to fifth $(120 \mathrm{~min})$ observation period which compared with the control group (Fig. 2). Moreover, the positive control group (diazepam $1 \mathrm{mg} / \mathrm{kg}$ ) decrement a similar modification to that observed with MEPH (Table 3).

\section{Rota-rod test}

In the rota-rod test the effect of MEPH (after $30 \mathrm{~min}$ of oral administration) at 200, 350, and $500 \mathrm{mg} / \mathrm{kg}$ statistically significant $(p<0.001)$ increase the number of falls whereas decrease the performance time at the same manner (Fig. 3). The muscle relaxant effects were similar to the positive

Table 4 The effect of MEPH on rota-rod test in mice

\begin{tabular}{llll}
\hline Treatment & Dose $(\mathrm{mg} / \mathrm{kg})$ & Performance time $(\mathrm{s})$ & Number of falls \\
\hline Control & $0.1 \mathrm{ml} / \mathrm{mouse}$ & $176.00 \pm 1.89$ & $1.40 \pm 0.74$ \\
Diazepam & 1 & $152.00 \pm 1.54^{* * *}$ & $14.60 \pm 0.40^{* * *}$ \\
$\mathrm{MEPH}$ & 50 & $174.40 \pm 1.72$ & $2.00 \pm 0.89$ \\
$\mathrm{MEPH}$ & 200 & $137.00 \pm 1.22^{* * *}$ & $15.20 \pm 0.73^{* * *}$ \\
$\mathrm{MEPH}$ & 350 & $138.60 \pm 1.07^{* * *}$ & $13.80 \pm 0.73^{* * *}$ \\
MEPH & 500 & $116.40 \pm 1.28^{* * *}$ & $17.00 \pm 0.63^{* * *}$ \\
\hline
\end{tabular}

Each value is presented as the mean \pm SEM $(n=10), \mathrm{MEPH}=$ Methanol extract of Persicaria hydropiper leaves. " ${ }^{\prime * * *} p<0.001,{ }^{* *} p<0.01,{ }^{*} p<0.05$ vs control group (Dunnett's test)" 


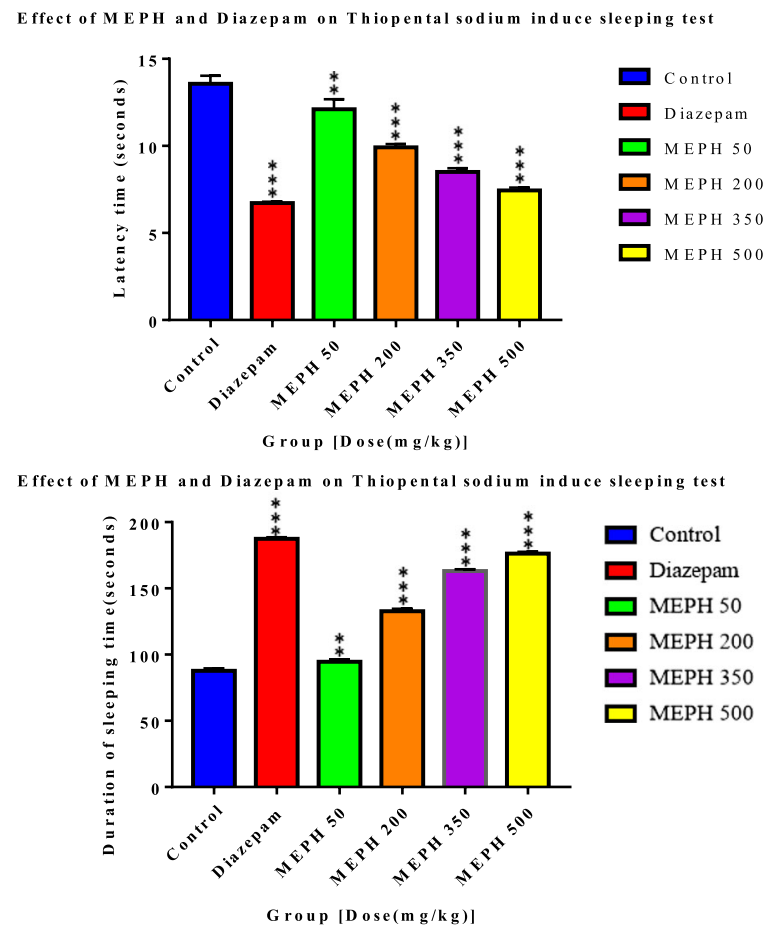

Fig. 4 The effect of MEPH on the Thiopental sodium induce sleeping test (Latency time and sleeping time) in mice

control group (diazepam $1 \mathrm{mg} / \mathrm{kg}$ ) which compared with the control group (Table 4 ).

\section{Thiopental sodium-induced sleeping time test}

In thiopental sodium-induced sleeping time test, significant $(p<0.001)$ decreased the onset of sleep observed. Additionally, significant $(p<0.001)$ increase in duration of total sleeping time observed in mice treated with $\mathrm{MEPH}$ at 200, 350, and $500 \mathrm{mg} / \mathrm{kg}$ when compared with the control group (Fig. 4). The positive control group (diazepam $1 \mathrm{mg} / \mathrm{kg}$ ) also produced a similar effect as well as MEPH (Table 5).

Table 5 The effect of MEPH on thiopental sodium-induced sleeping time test in mice

\begin{tabular}{llll}
\hline Treatment & $\begin{array}{l}\text { Dose } \\
(\mathrm{mg} / \mathrm{kg})\end{array}$ & $\begin{array}{l}\text { Onset of action } \\
(\mathrm{min})\end{array}$ & $\begin{array}{l}\text { Duration of sleeping } \\
\text { time }(\mathrm{min})\end{array}$ \\
\hline Control & $0.1 \mathrm{ml} / \mathrm{mouse}$ & $13.57+0.45$ & $87.80+1.85$ \\
Diazepam & 1 & $6.72+0.06^{* * *}$ & $187.40+1.12^{* * *}$ \\
MEPH & 50 & $12.10+0.57^{* *}$ & $94.60+1.80^{*}$ \\
MEPH & 200 & $9.92+0.19^{* * *}$ & $132.80+1.85^{* * *}$ \\
MEPH & 350 & $8.50+0.22^{* * *}$ & $163.00+1.37^{* * *}$ \\
MEPH & 500 & $7.44+0.16^{* * *}$ & $176.20+1.35^{* * *}$ \\
\hline
\end{tabular}

Each value is presented as the mean \pm SEM $(n=10), \mathrm{MEPH}=$ Methanol extract of Persicaria hydropiper leaves. " ${ }^{* * *} p<0.001,{ }^{* *} p<0.01,{ }^{*} p<0.05$ vs control group (Dunnett's test)"

\section{Anxiolytic activity test}

Elevated plus-maze test

In the elevated plus-maze, mice treated with $\mathrm{MEPH}$ preferred the open arms of the plus-maze and were found to be devoid of open arms avoidance (Fig. 5). Administration of MEPH at the doses of 50, 200, 350, and $500 \mathrm{mg} / \mathrm{kg}$ to the mice causes the statistically significant $(p<0.001)$ to increase the frequency of the open arms entries and time spent in open arms when compared with the control group. The positive control group (diazepam $1 \mathrm{mg} / \mathrm{kg}$ ) showed the similar effect as MEPH (Table 6).

\section{Light-dark box test}

In light-dark box test, administration of $\mathrm{MEPH}$ at $50 \mathrm{mg} / \mathrm{kg}$ dose of MEPH showed the significant $(p<0.001)$ in time spent in light compartments. On the other hand, 200, 350 and $500 \mathrm{mg} / \mathrm{kg}$ showed significantly $(p<0.001)$ increase the latency time, the number of transitions and time spent in light compartments comparable with the control group (Fig. 6). The similar effect observed in mice treated with diazepam (1 mg/kg) (Table 7$)$.

\section{Hole-board test}

In the hole-board test, the tendency of head dips significantly $(p<0.001)$ decrease in the mice treated with MEPH (after $30 \mathrm{~min}$ of oral administration) at 200, 350, and $500 \mathrm{mg} / \mathrm{kg}$ while compared with the control group (Fig. 7). The similar effect found in mice treated with diazepam $(1 \mathrm{mg} / \mathrm{kg})$. No significant effects observed at $50 \mathrm{mg} / \mathrm{kg}$ dose (Table 8).

\section{Marble-burying test}

In the marble-burying test, after oral administration of $200 \mathrm{mg} / \mathrm{kg}$ (after $30 \mathrm{~min}$ ) of MEPH showed the behavioral state of mice significantly $(p<0.05)$ reduced by the number of burying. Meanwhile, the doses of 350 , and $500 \mathrm{mg} / \mathrm{kg}$ exerted statistically significant $(p<0.001)$ decreased the number of burying (Fig. 8) as well as the positive control group (diazepam $1 \mathrm{mg} / \mathrm{kg}$ ) when compared with the control group (Table 9).

\section{Discussion}

The medicinal plant offers as a source of well accessible, cheap and efficient medicine earliest time from ancient people. Various ethnomedicinal plants have been found to endowed neurobehavioral state and act as an alternative option of modern medicine. Our present study focused on investigation the CNS effect of MEPH. The result demonstrated that MEPH shows the sedative and anxiolytic effect on the CNS. In acute toxicity test we observed that oral 

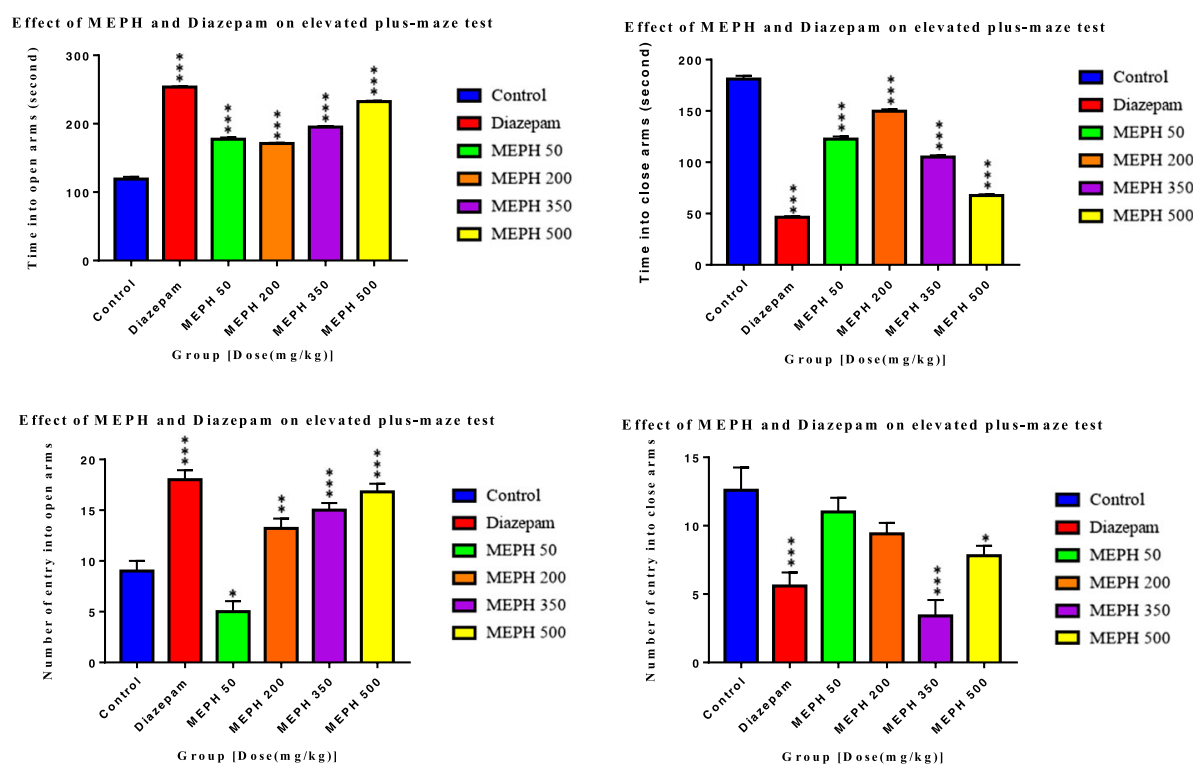

Fig. 5 The effect of MEPH on elevated plus-maze test (Time spent in open arms; Number of entries in open arms; Time spent in close arms; Number of entries in close arms) in mice

administration of MEPH did not produce any visible sign of delay toxicity, behavioral changes, allergic manifestations (skin, rash, itching), and mortality during the observation period of $72 \mathrm{~h}$. Thus it is authentic that MEPH non-toxic at our experimental doses is $750 \mathrm{mg} / \mathrm{kg}$. Our preliminary phytochemical screening deep-rooted and proposed that the presence of alkaloids, flavonoids, carbohydrates, glycosides, tannins, saponins, and steroids in the MEPH (Table 1). There are several experimental investigations which demonstrated that the rich plant extracts contain alkaloids and flavonoids possess sedative and anxiolytic properties mediated through their affinity (in vitro) with the benzodiazepine site of the GABAergic complex system are direct or indirect modulators of this receptor [24]. Besides, nonspecific CNS depression may also be associated with tannin. Hence, it observed from the above mentioned phytochemical presence in the MEPH may devote the sedative and anxiolytic effects on the CNS.
We evoked our experiment of the sedative effects of MEPH by observing the spontaneous locomotor activity of mice both the open field and hole cross test. In these tests, sedative properties of diazepam will produce both decreases in the number of square cross movements and expound in the new environment. This experimental data demonstrated that the sedative activity of MEPH conceives the satisfactory behavioral changed on the open field test (Table 2).

A notable disparity observed of hole crosses in the hole cross test in mice. MEPH successfully decreased the movements of hole cross by mice. Furthermore, similar types of responses found in diazepam treatment in mice. This observation proves that MEPH significantly modifies the movements of mice in hole cross method. Sedative activity accompanied by the behavioral effects and this include decreased the number of crosses (Table 3). This manner demonstrates the characteristics of sedative activity of benzodiazepine (BDZ) compounds.

Table 6 The effect of MEPH on elevated plus-maze test in mice

\begin{tabular}{llllll}
\hline Treatment & Dose $(\mathrm{mg} / \mathrm{kg})$ & Time spend in open arms $(\mathrm{s})$ & Entries in open arms $(\mathrm{s})$ & Time spend in close arms $(\mathrm{s})$ & Entries in close arms $(\mathrm{s})$ \\
\hline Control & $0.1 \mathrm{ml} / \mathrm{mouse}$ & $119.00 \pm 3.31$ & $8.60 \pm 0.98$ & $181.00 \pm 3.31$ & $16.40 \pm 0.81$ \\
Diazepam & 1 & $253.60 \pm 1.03^{* * *} 1.00^{* * *}$ & $18.00 \pm 0.94^{* * *}$ & $46.40 \pm 1.03^{* * *}$ & $1.80 \pm 0.37^{* * *}$ \\
MEPH & 50 & $177.40 \pm 2.50^{* * *}$ & $4.40 \pm 0.40^{*}$ & $122.60 \pm 2.50^{* * *}$ & $1.80 \pm 0.58$ \\
MEPH & 200 & $171.00 \pm 1.04^{* * *}$ & $8.80 \pm 0.58^{* *}$ & $149.80 \pm 1.77^{* * *}$ & $6.60 \pm 0.51$ \\
MEPH & 350 & $195.00 \pm 1.70^{* * *}$ & $11.40 \pm 0.51^{* * *}$ & $105.00 \pm 1.70^{* * *}$ & $8.80 \pm 1.02^{* * *}$ \\
MEPH & 500 & $232.40 \pm 1.12^{* * *}$ & $13.60 \pm 0.60^{* * * * *}$ & $67.60 \pm 1.12^{* * *}$ & $4.60 \pm 1.32^{*}$
\end{tabular}

Each value is presented as the mean \pm SEM $(n=10), \mathrm{MEPH}=$ Methanol extract of Persicaria hydropiper leaves. ${ }^{\mu * * *} p<0.001,{ }^{* * *} p<0.01,{ }^{*} p<0.05$ vs control group (Dunnett's test)" 


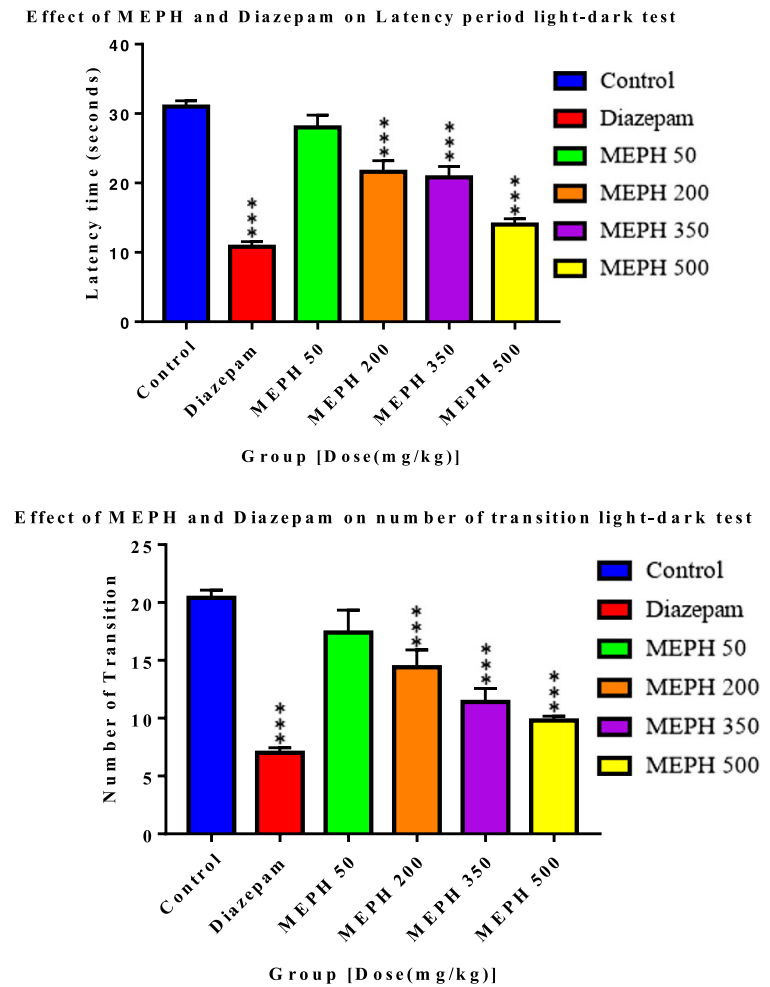

Fig. 6 The effect of MEPH on light-dark box test (Latency time; Transition; Time spent in light part; Time spent in dark part) in mice

The rota-rod test is a widely accepted method to evaluate the muscle relaxant effect in animals' model. Our results manifested that treatment with $\mathrm{MEPH}$ markedly increases the number of falling and decreased the performing time of mice on the rotating rod (Table 4). It well documented that some benzodiazepines like diazepam cause muscle relaxants, the reduction of ambulatory movements and sedation, thus diminishing the performance of mice in the rota-rod. As expected, we also found that diazepam caused muscle relaxation of the animals causing an increase of the falling time in the rota-rod. This same manner of the effect produced by MEPH and diazepam influenced us to conceive that MEPH can induce the sedative effects both affecting the general activity and the motor coordination of experimental mice. Our above evidence has further promoted the experimental results found in thiopental sodium-induced sleeping time observation test. This test is a classical method in behavioral pharmacology to investigate the sedative properties. In our study, the TS injection significant modified the latency to reduce sleep as well as increasing the duration of sleeping time (Table 5). As expected, similar types of effects accomplished by the administration with diazepam. Substantial evidence revealed that the CNS depressant such as TS bind to the gamma amino butyric acid type $A$ $\left(\mathrm{GABA}_{\mathrm{A}}\right)$ receptor complex and potential gamma aminobutyric acid (GABA) mediated hyperpolarization of postsynaptic neurons [25].

The putative anxiolytic activity was evaluated to perform with the elevated plus-maze light-dark box, hole-board, and marble-burying test. In the EPM test, mice treated with MEPH showed significant results in both the percentage of entries and the percentage of time spent in the open arms of the maze. Similar observations found to the experimental protocol adopted validated by the use of a standard anxiolytic agent (diazepam) which significantly increased both the number of open arm entries and the total time spent in the open arm entries and the total time spent in the open arms (Table 6). The anxiolytic effect evidence through the light-dark test. This model is popular for evaluating anxiety. It has developed for predicting the potency of the clinically used compound. It has assumed that the time mice spent on the illuminated side of the box are the most useful and consistent parameter of anxiety. The present study also showed that MEPH increase the time in the light compartment suggested anxiolytic properties (Table 7). The hole-board model offers a simple method to measure the response of rodents to an unfamiliar environment that can detect anxiolytic effects. Although this experiment is advantageous due to its methodological simplicity and several behavioral responses of an animal when exposed to an unfamiliar environment, it may readily observe and quantify. It found that the head-dipping behavior of the animals is directly

Table 7 The effect of MEPH on light-dark box test in mice

\begin{tabular}{|c|c|c|c|c|c|}
\hline Treatment & Dose (mg/kg) & Latency time (s) & Transition & Time spent in the light compartment(s) & Time spent in the dark compartment(s) \\
\hline Control & $0.1 \mathrm{ml} / \mathrm{mouse}$ & $31.00 \pm 0.83$ & $20.40 \pm 0.67$ & $248.80 \pm 1.71$ & $51.20 \pm 2.43$ \\
\hline Diazepam & 1 & $10.00 \pm 0.31^{* * *}$ & $7.00 \pm 0.44^{* * *}$ & $92.60 \pm 1.43^{* * *}$ & $207.40 \pm 1.43^{* * *}$ \\
\hline MEPH & 50 & $28.20 \pm 0.37$ & $19.40 \pm 0.40$ & $226.80 \pm 1.82^{* * *}$ & $72.20 \pm 1.15^{* * *}$ \\
\hline MEPH & 200 & $26.00 \pm 0.31^{* * *}$ & $16.40 \pm 0.67^{* * *}$ & $225.00 \pm 1.58^{* * *}$ & $105.00 \pm 1.58^{* * *}$ \\
\hline MEPH & 350 & $21.00 \pm 0.31^{* * *}$ & $11.40 \pm 0.98^{* * *}$ & $149.20 \pm 1.80^{* * *}$ & $105.60 \pm 1.16^{* * *}$ \\
\hline MEPH & 500 & $13.80 \pm 0.73^{* * *}$ & $9.80 \pm 0.37^{* * *}$ & $101.80 \pm 1.39^{* * *}$ & $198.20 \pm 1.39^{* * *}$ \\
\hline
\end{tabular}

Each value is presented as the mean \pm SEM $(\mathrm{n}=10), \mathrm{MEPH}=$ Methanol extract of Persicaria hydropiper leaves. ${ }^{\mu * * *} p<0.001,{ }^{* *} p<0.01,{ }^{*} p<0.05$ vs control group (Dunnett's test)" 


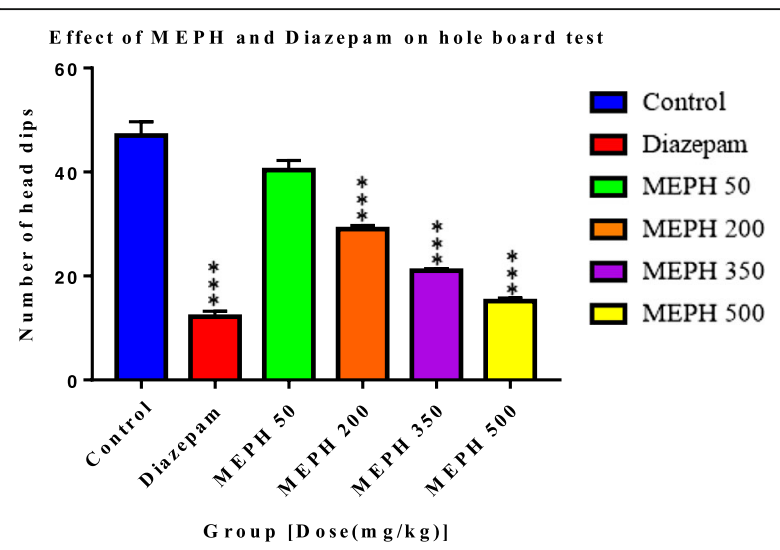

Fig. 7 The effect of MEPH on hole board test (number of head dips) in mice

related to their emotional state [26]. Based on this observation, it suggested that the expression of an anxiolytic state found to correlate with the anxiolytic effects of mice decrease in the number of head dips. In this model, the anxiolytic activity ensures through the administration of $\mathrm{MEPH}$ induced a decrease in the number of head dips (Table 8). The effect of anxiolytic agents is opening the GABA-activated chloride channels which enhancing the response GABA receptor. The anxiolytic effect directly related to the activation of GABA receptor. The marbleburying test is one of the most popular used animal models for anxiolytic behavior. Results obtained in the burying behavior test showed that MEPH, as well as diazepam $(1 \mathrm{mg} / \mathrm{kg})$ decreased the burying behavior, an effect considered as an anxiolytic-like action (Table 9).

The anxiolytic, and sedative activities of benzodiazepines like diazepam are particularly attributed, enhancing the action of gamma-aminobutyric acid $\left(G_{A B A}\right)$. Considering the structure modification of $\mathrm{GABA}_{\mathrm{A}}$ receptor augment the receptor activity. Benzodiazepines bind at the alpha subunit and take a part of opening events of chloride ion which associated conductance and inhibition of the action potential. The pharmacological effects of MEPH are

Table 8 The effect of MEPH on hole-board test in mice

\begin{tabular}{lll}
\hline Treatment & Dose $(\mathrm{mg} / \mathrm{kg})$ & Number of head dips \\
\hline Control & $0.1 \mathrm{ml} / \mathrm{mouse}$ & $42.40 \pm 0.92$ \\
Diazepam & 1 & $12.20 \pm 0.58^{* * *}$ \\
MEPH & 50 & $40.40 \pm 0.51$ \\
MEPH & 200 & $29.00 \pm 0.54^{* * *}$ \\
MEPH & 350 & $21.00 \pm 0.63^{* * *}$ \\
MEPH & 500 & $15.20 \pm 0.58^{* * *}$ \\
\hline
\end{tabular}

Each value is presented as the mean \pm SEM $(n=10), M E P H=$ Methanol extract of Persicaria hydropiper leaves. ${ }^{* * * *} p<0.001,{ }^{* *} p<0.01,{ }^{*} p<0.05$ vs control group (Dunnett's test)"

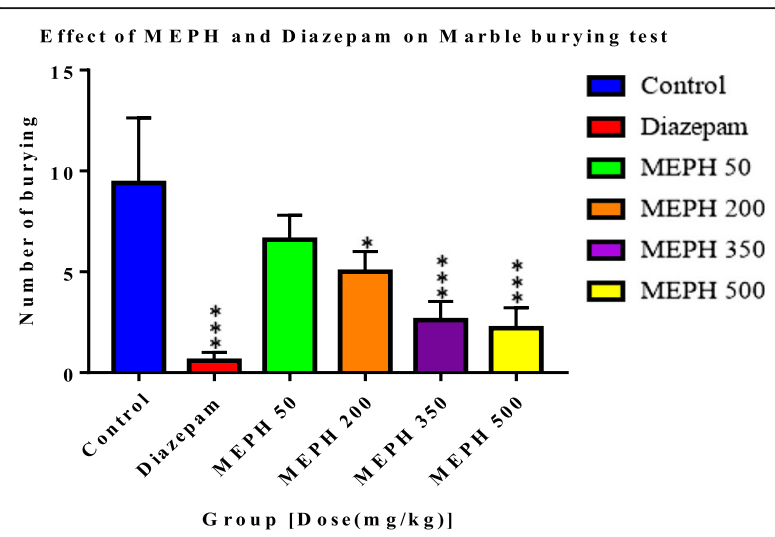

Fig. 8 The effect of MEPH on marble burying test (number of marble burying) in mice

purposed to be mediated by the $\mathrm{GABA}_{\mathrm{A}}$ receptor, BZDs and non-BZD agents produce sedative and anxiolytic activities by stimulating the $\mathrm{GABA}_{\mathrm{A}}$ receptor. The sedative and anxiolytic effects of benzodiazepines may be due to the direct activation of glycine synapses in the brain. The explanation of our tested extract mechanism of action may similar result as well to diazepam.

\section{Conclusions}

In conclusion, the present findings in our study indicate that MEPH possesses strong sedative and anxiolytic activity. Anxiety and sedation principally mediated by the $\mathrm{GABA}_{\mathrm{A}}$ receptor complex in the CNS, which is also involved in other physiological functions related to behavior, and in several psychological and neurological disorders. Furthermore, evidence obtained from the present study may justify that the use of $P$. hydropiper in traditional medicine for the treatment of insomnia, depression, and neurodegenerative diseases. However, further studies are needed to isolate the bioactive compound(s) and demonstrate the precise molecular mechanisms responsible for the pharmacological activities of $\mathrm{MEPH}$.

Table 9 The effect of MEPH on marble-burying test in mice

\begin{tabular}{lll}
\hline Treatment & Dose $(\mathrm{mg} / \mathrm{kg})$ & Number of burying \\
\hline Control & $0.1 \mathrm{ml} / \mathrm{mouse}$ & $9.40 \pm 1.56$ \\
Diazepam & 1 & $0.60 \pm 0.40^{* * *}$ \\
$\mathrm{MEPH}$ & 50 & $6.60 \pm 1.20$ \\
$\mathrm{MEPH}$ & 200 & $5.00 \pm 1.00^{*}$ \\
$\mathrm{MEPH}$ & 350 & $2.60 \pm 0.92^{* * *}$ \\
$\mathrm{MEPH}$ & 500 & $2.20 \pm 1.02^{* * *}$ \\
\hline
\end{tabular}

Each value is presented as the mean \pm SEM $(n=10), M E P H=$ Methanol extract of Persicaria hydropiper leaves. ${ }^{\prime * * *} p<0.001,{ }^{* *} p<0.01,{ }^{*} p<0.05$ vs control group (Dunnett's test)" 


\section{Abbreviations}

BZN: Benzodiazepine; CNS: Central Nervous System; GABA: Gamma Amino butyric Acid; ICDDR,B: International Center for Diarrheal Disease and Research, Bangladesh; MEPH: Methanol extract of Persicaria hydropiper; TS: Thiopental Sodium

\section{Acknowledgements}

The authors are grateful to Professor Dr. Bidyut Kanti Datta, Chairman, Department of Pharmacy, Stamford University Bangladesh for his permission to use the facilities of the Pharmacology and Phytochemistry Laboratory.

\section{Funding}

This research work did not have any particular funding. All the studies had been self-funded by author and co-authors.

\section{Availability of data and materials}

Not applicable.

\section{Authors' contributions}

Md. SAM designed and coordinated acute toxicity test, open field test, hole cross test, rota-rod test, thiopental sodium sleeping test, light-dark box test, hole board test, marble burying test and interpreted results. SMML conducted phytochemical analysis. Md. SAM done statistical analysis, draw graph and drafted the manuscript. Both authors read and approved the final manuscript.

\section{Ethics approval and consent to participate}

All the experimental mice were treated following the Ethical Principles and Guidelines for Scientific Experiments on Animals (1995) formulated by The Swiss Academy of Medical Sciences and the Swiss Academy of Sciences. The Institutional Animal Ethical Committee (SUB/IAEC/14.05) of Stamford University Bangladesh approved all experimental rules.

\section{Consent for publication}

Not applicable.

\section{Competing interests}

The authors report no conflicts of interest. The authors alone are responsible for the content and writing of the paper.

\section{Received: 29 June 2017 Accepted: 10 October 2017}

Published online: 25 October 2017

\section{References}

1. Mabberley D. Mabberley's plant-book: a portable dictionary of plants, their classifications and uses. 2008 [cited 2017 Jun 26]. Available from: https:// www.cabdirect.org/cabdirect/abstract/20083188502.

2. Ayaz M, Junaid M, Subhan F. Heavy metals analysis, phytochemical, phytotoxic and anthelmintic investigations of crude methanolic extract, subsequent fractions and crude saponins from. BMC, 2014 [cited 2017 Jun 26]; Available from: https://bmccomplementalternmed.biomedcentral.com/ articles/10.1186/1472-6882-14-465.

3. Huq A, Jamal J, Stanslas J. Ethnobotanical, phytochemical, pharmacological, and toxicological aspects of Persicaria Hydropiper (L.) delarbre. EvidenceBased Complement. 2014 [cited 2017 Jun 26]; Available from: https://www. hindawi.com/journals/ecam/2014/782830/abs/.

4. Hasan $\mathrm{S}$, Hossain M, Akter R. DPPH free radical scavenging activity of some Bangladeshi medicinal plants. Med. plants. 2009 [cited 2017 Jun 26]; Available from: http://www.academicjournals.org/journal/JMPR/article-abstract/2FD0D6D15264.

5. Rahmatullah M, Mukti I, Haque A. An ethnobotanical survey and pharmacological evaluation of medicinal plants used by the Garo tribal community living in Netrakona district, Bangladesh. Adv. Nat. 2009 [cited 2017 Jun 26]; Available from: https://www.researchgate.net/profile/Akm_ Haque2/publication/271531538_An_Ethnobotanical_Survey_and_ Pharmacological_Evaluation_of_Medicinal_Plants_used_by_the_Garo_ Tribal_Community_living_in_Netrakona_district_Bangladesh/links/ 54cc5fde0cf298d6565a7e3f/An-Ethnobotanical-Survey-and-PharmacologicalEvaluation-of-Medicinal-Plants-used-by-the-Garo-Tribal-Community-living-inNetrakona-district-Bangladesh.pdf.

6. Shahidullah M, Al-Mujahidee M, Uddin S. Medicinal plants of the Santal tribe residing in Rajshahi district, Bangladesh. Am-Eur J Sustain. 2009 [cited 2017
Jun 26]; Available from: http://www.aensiweb.net/AENSIWEB/aejsa/aejsa/ 2009/220-226.pdf.

7. Kadir M, Sayeed M, Mia M. Ethnopharmacological survey of medicinal plants used by traditional healers in Bangladesh for gastrointestinal disorders. J. Ethnopharmacol. 2013 [cited 2017 Jun 26]; Available from: http://www. sciencedirect.com/science/article/pii/S0378874113001189.

8. Khatun A, Imam M, Rana M. Antinociceptive effect of methanol extract of leaves of Persicaria Hydropiper in mice. BMC [Internet]. 2015 [cited 2017 Jun 26]; Available from: https://bmccomplementalternmed.biomedcentral.com/ articles/10.1186/s12906-015-0558-y.

9. Heinrich M, Teoh H. Galanthamine from snowdrop-the development of a modern drug against Alzheimer's disease from local Caucasian knowledge. J. Ethnopharmacol. 2004 [cited 2017 Jun 26]; Available from: http://www. sciencedirect.com/science/article/pii/S037887410400073X.

10. Hashim N, Abas F, Shaari K, Lajis N. LC-DAD-ESIMS/MS characterization of antioxidant and anticholinesterase constituents present in the active fraction from Persicaria Hydropiper. LWT-Food Sci. 2012 [cited 2017 Jun 26]; Available from: http://www.sciencedirect.com/science/article/pii/S0023643811003768.

11. Novel insights into the pharmacology of flavonoids. Phytotherapy 2013 [cited 2017 Jun 26]; Available from: http://onlinelibrary.wiley.com/doi/10. 1002/ptr.5023/full.

12. Oany A, Hossain M, Islam R, Emran A. A preliminary evaluation of cytotoxicity, antihyperglycemic and antinociceptive activity of Polygonum Hydropiper L. ethanolic leaf extract. Clin. Phytoscience. 2017 [cited 2017 Jun 26]; Available from: http://link.springer.com/article/10.1186/s40816-016-0016-5.

13. Hashim NN, Abas F, Shaari K. Antioxidant and xanthine oxidase inhibitory activities of Persicaria Hydropiper. Int. J. 2013 [cited 2017 Jun 26]; Available from: http://www.tandfonline.com/doi/abs/10.1080/10942912.2011.575497.

14. Yang $Y, Y u T$, Jang $H$, Byeon $S$, Song $S$. In vitro and in vivo antiinflammatory activities of Polygonum Hydropiper methanol extract. J. 2012 [cited 2017 Jun 26]; Available from: http://www.sciencedirect.com/science/ article/pii/S0378874111008701.

15. Sharif S, Shahriar M, Haque M, Chowdhury Z. In-vitro antioxidant activities, antinociceptive and neuropharmacological activities of Polygonum Hydropiper. Invitro. 2013 [cited 2017 Sep 4]; Available from: http://www.academia.edu/ download/32788825/In-vitro_antioxidant_activities_anti-nociceptive_and_ neuropharmacological_activities_of_Polygonum_hydropiper.pdf.

16. Antinociceptive activity of Mirabilis jalapa in mice. Ethnopharmacol. 2008 [cited 2017 Jun 26]; Available from: http://www.sciencedirect.com/science/ article/pii/S0378874108004297.

17. Simlai A, Roy A. Biological activities and chemical constituents of some mangrove species from Sundarban estuary: an overview. Pharmacogn. Rev. 2013 [cited 2017 Jun 26]; Available from: https://www.ncbi.nlm.nih.gov/ pmc/articles/PMC3841995/.

18. Williamson E, Okpako D, Evans F. Selection, preparation and pharmacological evaluation of plant material. 1996 [cited 2017 Jun 26]. Available from: https://www.google.com/books?hl=en\&lr=\&id= tTELyhJ $\times O o C \& o i=f n d \& p g=P A 1 \& d q=$ Williamson+EM,+Okpako+DT,+Evans +FJ:+Selection,+preparation+and+pharmacological+evaluation+of+plant +material,+vol.+1:+John+Wiley+\%26+Sons\%3B+1996.\&ots= KbA9RZrbz3\&sig=-dxTDn5ppjHmMErv3p3Str2r6xc.

19. Komada M, Takao K, Miyakawa T. Elevated plus maze for mice. J. Vis. 2008 [cited 2017 Sep 7]; Available from: https://www.ncbi.nlm.nih.gov/pmc/ articles/PMC2762911/

20. Bourin M, Hascoet M. The mouse light/dark box test. Eur. J. Pharmacol. 2003 [cited 2017 Jun 26]; Available from: http://www.sciencedirect.com/science/ article/pii/S0014299903012743

21. Crawley J, Goodwin F. Preliminary report of a simple animal behavior mode for the anxiolytic effects of benzodiazepines. Pharmacol. Biochem. Behav. 1980 [cited 2017 Jun 26]; Available from: http://www.sciencedirect.com/ science/article/pii/0091305780900672

22. López-Rubalcava C, Hen R, Cruz S. Anxiolytic-like actions of toluene in the burying behavior and plus-maze tests: differences in sensitivity between 5-HT 1B knockout and wild-type mice. Behav. Brain Res. 2000 [cited 2017 Jun 26]; Available from: http://www.sciencedirect.com/science/article/pii/S0166432800002412.

23. Fernández S, Wasowski C, Paladini A. Sedative and sleep-enhancing properties of linarin, a flavonoid-isolated from Valeriana Officinalis. Pharmacology. 2004 [cited 2017 Jun 26]; Available from: http://www. sciencedirect.com/science/article/pii/S009130570300368X

24. Kahnberg $\mathrm{P}$, Lager $\mathrm{E}$, Rosenberg $\mathrm{C}$. Refinement and evaluation of a pharmacophore model for flavone derivatives binding to the 
benzodiazepine site of the GABAA receptor. J. Med. 2002 [cited 2017 Jun 26]; Available from: http://pubs.acs.org/doi/abs/10.1021/jm020839k.

25. Moniruzzaman M, Rahman A, Ferdous A. Evaluation of sedative and hypnotic activity of ethanolic extract of Scoparia Dulcis Linn. Based complement. ... 2015 [cited 2017 Jun 26]; Available from: https://www. hindawi.com/journals/ecam/2015/873954/abs/.

26. Ebert B, Wafford K, Deacon S. Treating insomnia: current and investigational pharmacological approaches. Pharmacol. Ther. 2006 [cited 2017 Jun 26]; Available from: http://www.sciencedirect.com/science/article/pii/S0163725806001094.

Submit your manuscript to a SpringerOpen ${ }^{\circ}$ journal and benefit from:

- Convenient online submission

- Rigorous peer review

- Open access: articles freely available online

- High visibility within the field

- Retaining the copyright to your article

Submit your next manuscript at $\boldsymbol{\sim}$ springeropen.com 